\title{
Ciencia y sabiduría: ¿tenemos razones para ser optimistas?
}

\author{
Melchor Sánchez Mendiola
}

Coordinador de Desarrollo Educativo e Innovación Curricular en la Universidad Nacional Autónoma de México (UNAM). Doctor en Ciencias, Educación en Ciencias de la Salud por la UNAM; maestro en Educación en Profesiones de la Salud por la Universidad de Illinois en Chicago, EUA. Médico Pediatra por la Universidad del Ejército y Fuerza Aérea Mexicanos (UDEFA). Profesor de Carrera Titular C de Tiempo Completo Definitivo en la División de Estudios de Posgrado de la Facultad de Medicina, UNAM. 
Revista Digital Universitaria

Vol. 20, Núm. 3, mayo-junio 2019

"La magia de un hombre es la ingeniería de otro.

'Sobrenatural' es una palabra inválida".

Robert A. Heinlein

"El aspecto más triste de la vida en la actualidad es

que la ciencia acumula conocimiento

más rápido de lo que la sociedad acumula sabiduría".

Isaac Asimov

El siglo XXI está lleno de términos que pueden representar mucho y a la vez poco, dependiendo de quién los escucha y quién los dice. ¿Cuántas veces ha escuchado el lector las palabras economía del conocimiento, globalización, cambio climático, big data, pensamiento de sistemas, sustentabilidad, medicina de precisión, bono demográfico, entre muchas otras? Cada uno de estos términos tiene su historia (o historias, ya que algunos tienen presencia en múltiples disciplinas) y su significado se modifica conforme pasa el tiempo, a ritmos diferentes dependiendo de la sociedad en que se expresa. Valga el ejemplo del multicitado término economía del conocimiento, ¿qué quiere decir exactamente? Lo hemos oído en todo tipo de discursos académicos, políticos y pláticas de sobremesa, pero ¿quiénes nos tomamos la molestia de ir más allá del primer hit de Google o de Wikipedia, a revisar el concepto en los frecuentemente densos artículos científicos y libros académicos? Sin minimizar el enorme impacto que han tenido en nuestras vidas (en lo personal, académico y laboral) los motores de búsqueda y los recursos digitales, creo que como ciudadanos responsables debemos hacer el esfuerzo por profundizar cuando nos encontramos con estos términos. Su uso ocasiona que adquieran vida propia y, a veces, se conviertan en lemas y gritos de batalla de organizaciones, universidades e incluso gobiernos, con la consecutiva comprensión superficial del concepto sin reflexión.

Al revisar cualquier referencia formal del tema, encontramos que economía del conocimiento tiene múltiples significados e incluye una gran variedad de actividades e interpretaciones dependiendo del "paraguas" conceptual y paradigma desde el cual es analizado (Powell y Snellman, 2004), con una serie de matices que jamás captaríamos si nos limitásemos a lo que se dice en los discursos. Las primeras referencias al tema se remiten al inicio de la década de los años sesenta, y estoy seguro de que las personas que vivieron en esa década tuvieron una percepción muy diferente de lo que es economía y lo que es conocimiento, de la que tenemos en la segunda década del siglo XXI. En la actualidad la economía del conocimiento puede ser una aspiración, un logro, una amenaza o algo inalcanzable, dependiendo de quién y cómo use el término.

El mensaje que deseo transmitir al lector es que los avances de la ciencia y del conocimiento pueden percibirse de forma totalmente diferente dependiendo del momento en el tiempo y del contexto socioeconómico en que se analicen. Lo que hacemos hoy con nuestro teléfono celular (dizque inteligente, pero, eso sí, muy adictivo) sería impensable para nuestros padres en el siglo pasado, y seguramente lo que harán nuestros hijos y nietos con los dispositivos que reemplacen 
Revista Digital Universitaria

Vol. 20, Núm. 3, mayo-junio 2019

a los actuales rebasará con mucho lo que pensemos hoy. Una de mis pasiones durante la juventud y edad adulta ha sido la lectura de ciencia ficción, traigo el tema a colación porque los artículos de este número de la revista tocan múltiples campos del saber, y precisamente uno de ellos es el uso de la ciencia ficción en la educación. He leído muchos libros sobre el tema, sobre todo los de la llamada era dorada de la ciencia ficción, de autores como Isaac Asimov, Arthur C. Clarke, Robert E. Heinlein, Ray Bradbury, John W. Campbell y muchos otros (algunos de ellos que trascendieron el campo de la ciencia ficción a otras áreas de la corriente principal). Isaac Asimov fue uno de los héroes de mi adolescencia, me encantaba su agudo sentido del humor y su amplísimo conocimiento de todos los temas, y he leído una y otra vez varias de sus obras. Creo que las citas de Asimov y Heinlein con que inicio esta editorial, si bien fueron escritas hace muchas décadas, tienen total vigencia en la época actual.

Prácticamente cualquier tema de los explorados por los autores de este número de la RDU parecería magia a habitantes de nuestro pasado: el tratamiento de la retinopatía diabética, el sector hotelero y las pymes, el monitoreo atmosférico, el uso de Glass Cast y la literacidad visual, la programación con R, entre otros. Como dijo Robert Heinlein, la magia de una persona es ingeniería para otra $y$, desafortunadamente, una de las tragedias de la vida moderna es que sabemos cada vez más como especie, pero con inusitada frecuencia no utilizamos o malutilizamos el conocimiento adquirido. Tenemos cada vez mayor información y conocimiento acumulados, pero este aumento no ha ido acompañado de un incremento paralelo y de dimensiones similares en nuestra sabiduría, con las consecuencias visibles que tenemos en la actualidad: asimetría brutal de condiciones socioeconómicas, racismo, corrupción galopante, maltrato infantil, calentamiento global, contaminación y un muy largo etcétera. La montaña de datos con que contamos en la actualidad es una masa inerte e inútil si no se convierte en información (al darle sentido), en conocimiento (para la aplicación y generación de ideas), y finalmente en sabiduría. Ésta es el nivel último que pretendemos alcanzar para estar en condiciones de reflexionar sobre lo que nos ocurre como individuos y como sociedad, poder planear a corto, mediano y largo plazo, escuchar a las personas que tienen más preparación y experiencia en cada campo del saber para que auxilien la toma de decisiones, e intentar lograr un estado de balance, equidad y logro en términos de felicidad y plenitud.

La cantidad de variables que influyen en nuestra cotidianeidad es prácticamente infinita y, sin embargo, nos movemos en nuestro diario vivir de forma más o menos fluida, enfrentando las situaciones que nos genera la existencia con mayor o menor éxito. Invito a nuestros lectores a explorar los artículos de este número de la Revista (aun los que aparentemente no sean de interés inmediato para sus preferencias), ya que de la lectura de estas temáticas pueden surgir serendípicamente ideas, intereses, exploraciones que pueden llevar al crecimiento personal y de los que nos rodean. Todos tenemos algún familiar con diabetes, preocupémonos de que no pierda la vista; todos nos enfrentamos a una terrible contaminación atmosférica y de ruido, reflexionemos sobre sus efectos y cómo prevenir el daño que nos ocasionan, y así sucesivamente para cada uno de las materias analizadas en los artículos de divulgación que aparecen en este número. Incrementemos nuestro conocimiento, para poder desarrollar la sabiduría que reclaman nuestro planeta y los que lo habitamos. 
Revista Digital Universitaria

Vol. 20, Núm. 3, mayo-junio 2019

\section{Referencias}

* Powell, W. W.y Snellman, K. (2004). The Knowledge Economy. Annual Review of Sociology 30(1): $199-220$. Recuperado de: https://www.annualreviews.org/doi/abs/10.1146/annurev.soc.29.010202.100037.

\section{Cómo citar este artículo}

* Sánchez Mendiola, Melchor (2019). Ciencia y sabiduría: ¿tenemos razones para ser optimistas? Revista Digital Universitaria (RDU). Vol. 20, núm. 3 mayo-junio. Dol: http://doi.org/10.22201/ codeic.16076079e.2019.v20n3.a0 